BMJ Nutrition,

Prevention \& Health

\section{Adherence to dietary and physical activity guidelines among shift workers: associations with individual and work- related factors}

To cite: Kelly C, Nea FM, Pourshahidi LK, et al. Adherence to dietary and physical activity guidelines among shift workers: associations with individual and work-related factors. BMJ Nutrition, Prevention \& Health 2020;3:e000091. doi:10.1136/ bmjnph-2020-000091

- Additional material is published online only. To view, please visit the journal online (http://dx.doi.org/10.1136/ bmjnph-2020-000091).

For numbered affiliations see end of article.

Correspondence to Dr Ciara Kelly, Department of Public Health, Merlin Park Regional Hospital, Galway H91 YR71, Ireland; kellyc42@tcd.ie

Received 20 April 2020 Revised 28 July 2020 Accepted 30 July 2020 Published Online First 23 September 2020

Check for updates

(c) Author(s) (or their employer(s)) 2020. Re-use permitted under CC BY-NC. No commercial re-use. See rights and permissions. Published by BMJ.

\section{ABSTRACT}

Objectives Shift work is associated with adverse effects on the health and lifestyle behaviours of employees. This study aimed to examine factors associated with adherence among shift workers to selected indicators of dietary and physical activity guidelines.

Methods A cross-sectional study was conducted on 1300 shift workers. Data were collected using a 15 minute telephone-administered questionnaire. Logistic regression methods were used for data analysis.

Results Male shift workers $(p<0.001,0 R=0.55$, $95 \% \mathrm{Cl} 0.40$ to 0.74 ) and those of lower socioeconomic status ( $p=0.046,0 R=0.75,95 \% \mathrm{Cl} 0.57$ to 0.99 ) were significantly less likely to consume five or more daily servings of fruits and vegetables. Shift workers with access to workplace vending machines were significantly more likely to consume soft drinks at least weekly $(p=0.003,0 R=1.64,95 \% \mathrm{Cl} 1.18$ to 2.27 ). Middleaged shift workers $(p=0.012,0 R=0.65,95 \% \mathrm{Cl} 0.46$ to 0.91 ) and those reporting insufficient break times at work ( $\mathrm{p}=0.026,0 \mathrm{R}=0.69,95 \% \mathrm{Cl} 0.49$ to 0.96 ) were significantly less likely to be sufficiently active.

Conclusions Individual, work schedule and workplace environment related factors were independently associated with selected indicators of adherence to dietary and physical activity guidelines in this cohort of shift workers.

\section{INTRODUCTION}

Shift work is defined by the Council of the European Union' ${ }^{1}$ as 'any method of organising work in shifts whereby workers succeed each other at the same work stations according to a certain pattern'. Traditionally, only a limited proportion of the workforce was engaged in shift work-however, many employment sectors have now adopted shift work schedules. ${ }^{2}$ In $2010,17 \%$ of the workforce in the European Union was employed in shift work, ${ }^{3}$ a proportion which had increased to $21 \%$ by $2015 .{ }^{4}$ In Ireland, approximately $15 \%$ of the working population are employed in shift and/or night work. $^{2}$

\section{Key messages}

What this paper adds?

- This study has identified factors pertaining to the individual, shift work exposure and the workplace environment that were independently associated with adherence among a large cohort of shift workers employed on the island of Ireland to selected indicators of population dietary and physical activity guidelines.

- Overall, adherence among shift workers in this study to these guidelines was sub-optimal - less than half of the participants were adherent to each of the guideline indicators of interest.

- The optimisation of dietary intake and physical activity levels among shift workers should be a priority for occupational and public health medicine - insights provided by this study may inform the development of interventions to address this for shift workers, tailored according to individual and workrelated factors.

Shift work has been associated with adverse effects on the physical and mental health of those engaged in it-in particular, increased risks of being overweight or obese, the metabolic syndrome and other non-communicable diseases (NCDs) including type 2 diabetes mellitus, cardiovascular disease, gastrointestinal and mental health disorders. ${ }^{5}$ In 2019, the International Agency for Research on Cancer categorised 'night shift work' as a Group 2A carcinogen. ${ }^{7}$ The disruptive and irregular nature of shift work schedules may also adversely affect the worker's ability and motivation to maintain health-promoting lifestyle behaviours. ${ }^{8}$ Many such behaviours, including an unhealthy diet, physical inactivity, smoking, excess alcohol consumption, being overweight and having insufficient sleep are considered to be risk factors for 
NCDs and have been more frequently reported among shift workers. ${ }^{59}$ Shift work has been shown to adversely affect the quality and quantity of dietary intake as well as meal frequency, with greater meal skipping and unconventional meal timing reported among shift workers compared with non-shift workers. ${ }^{10}$ Shift workers may also have difficulty engaging in regular exercise due to factors such as time constraints, sleep disruption, fatigue, lack of availability of leisure facilities and opportunities to exercise outside of working hours, and internal factors such as individual motivation to exercise. ${ }^{11}$

The limited published data on the experience of Irish shift workers have demonstrated that shift work may negatively affect their health behaviours and psychosocial well-being. ${ }^{12}$ Factors relating to the work environment have been identified which may act as barriers or facilitators in their effect on the ability of Irish shift workers to maintain healthy lifestyle behaviours both at work and at home. Further evidence-based insights of this nature are required to inform the development of public and occupational health measures to optimise the health and health behaviours of shift workers. The aim of this study was to examine individual and work-related factors associated with adherence among shift workers to selected indicators of national dietary and physical activity guidelines.

\section{METHODS}

\section{Study design and participants}

This cross-sectional study was conducted on a population of 1300 shift workers from the Republic of Ireland (RoI) $(\mathrm{n}=850)$ and Northern Ireland $(\mathrm{NI})(\mathrm{n}=450)$, which was demographically, geographically and occupationally representative of the estimated 270000 shift workers on the island of Ireland. The study population was derived from a previous larger study commissioned by safefood entitled 'Managing Food on Shift Work', comprised of quantitative and qualitative components. ${ }^{13}$ The data for the original safefood study were collected by the market research company Millward Brown Ulster (MBU) using a 15 minute telephone-administered questionnaire, developed by the research team for the safefood study. The content of this study questionnaire was informed by the qualitative component of the safefood study, the published shift work literature and national dietary intake data. A random digit dial sample of telephone numbers in the RoI and NI was generated using a mathematical formula by MBU, then pulsed to ensure they were 'live' numbers. Random real numbers were then selected from the database via specialised telephone software. Eligibility criteria for this study included being aged 18 years or older and working in a shift work pattern at the time of contact. During the 15 minute telephone interview, participants were asked a series of questions (referring to the previous 1 month period of their lives) to obtain information on their demographic characteristics, shift work pattern, typical dietary intake, physical activity levels and workplace environment. The questionnaire used to collect data for the safefood study was reviewed prior to the commencement of this study, and variables relevant to the research question and the questions pertaining to those variables were chosen. The original questionnaire is available as online supplementary appendix 1 with the questions considered relevant for the current study indicated (highlighted in yellow).

\section{Data management}

On receipt of the raw data from the original safefood study variables not intended for use were removed and missing values were coded (these data were not included in the analysis of data for the current study). Selected variables were recoded into categorical variables. Age was recoded into three categories; $18-34$ years, 35-54 years and 55 +years, in order to examine age profiles of shift workers in relation to outcomes of interest. Body mass index (BMI), calculated based on self-reported height and weight measures, was recoded into four categories based on the WHO BMI classification system; $;^{14}$ underweight $\left(<18.50 \mathrm{~kg} / \mathrm{m}^{2}\right)$, normal weight $(18.50-24.99 \mathrm{~kg}$ / $\mathrm{m}^{2}$ ), overweight $\left(25.00-29.99 \mathrm{~kg} / \mathrm{m}^{2}\right)$ and obese $(\geq 30 \mathrm{~kg} /$ $\mathrm{m}^{2}$ ). Socioeconomic status (SES) was derived in the original safefood study from the occupation of the head of the household, categorised according to the National Readership Survey (2015) classification system ${ }^{15}$ into classes ABC1 and C2DE. ABC1 included those in the upper middle, middle and lower middle classes, while C2DE included those in the skilled working, working and non-working classes. Duration of exposure to shift work measured in years and the average length of shift measured in hours were recoded, respectively, into 'less than 8 years' and ' 8 years or more', and 'less than 8 hours', ' $8-11$ hours' and ' 12 or more hours'. The predominant shift pattern of participants was recoded into 'days', 'nights', 'rotating' and 'other' (which included split, inconsistent and equal day/afternoon/night rotating shifts)—online supplementary table 1, available as online-only supplementary material, provides further information on this categorisation.

Consumption of fruits, vegetables, wholegrains and soft drinks were selected as dietary outcomes of interest for this study, representing markers of adherence to Irish dietary guidelines. These were chosen following review of the shift work literature, and of dietary intake data and guidelines for the Irish adult population. These guidelines advise consumption of a minimum of five to seven daily servings of fruits and vegetables (unsweetened fruit juice, smoothies, tinned fruit and dried fruit are also counted) and three to five daily servings of foods from the 'wholemeal cereal and breads, potatoes (cooked any way), pasta and rice' group of the Irish food pyramid, ${ }^{16}$ as these are highly nutrient-dense foods associated with reductions in risk of several chronic diseases and overall mortality. ${ }^{17} 18$ The suboptimal compliance of the adult population of the RoI and NI with these specific dietary guidelines is well described, ${ }^{19-21}$ while lower intakes of fruit, vegetables, dietary fibre and various micronutrients have been 
observed among shift workers compared with non-shift day workers. ${ }^{22-24}$

Consumption of fruits and vegetables was recoded in a binary manner into those who consumed five or more daily servings of these foods and those who consumed them less frequently than this. Consumption of wholegrains (a food category which included 'brown pasta, brown rice, wholegrain bread, wholegrain cereals, and porridge' in the study questionnaire) was also recoded in a binary manner into those who consumed one or more daily servings of these foods and those who consumed them less frequently than this.

The frequency of consumption of soft drinks was recoded into those who consumed one or more servings of these beverages per week and those who consumed them less frequently than this, as Irish adults are advised to avoid daily consumption of soft drinks and to limit overall intake to a maximum of one or two servings per week. ${ }^{16}$

National and international physical activity guidelines advise adults to undertake a minimum 150 minutes of moderate-intensity aerobic physical activity per week. ${ }^{25} 26$ In this study, physical activity was recorded in minutes per week per participant based on self-reported frequency of episodes of moderate-to-vigorous physical activity performed per week and the average length of each. The total time engaged in physical activity per week was then calculated and categorised according to whether the participant was meeting the above guideline or not.

\section{Data analysis}

SPSS (IBM V.24) was used for data management and statistical analysis. A descriptive analysis of the study population was initially conducted. Pearson's $\chi^{2}$ tests were used to compare categorical variables and examine associations between these. Logistic regression methods were chosen for the analysis of this study as the selected outcomes were binary in nature, that is, meeting the relevant guideline or not. Univariable binary logistic regression analyses were then performed for the four (three dietary and one physical activity) outcomes of interest using the same independent variables for each outcome. Independent variables pertained to the individual (gender, age category, SES and BMI), shift work exposure (occupational sector, duration of shift work exposure, average shift length and predominant shift pattern) and the workplace environment (availability of food preparation, food storage and leisure facilities, vending machines and adequate break times, whether participants were satisfied with healthy food options at work and whether they felt their workplace helped them lead a healthy lifestyle). Health and social work was chosen as the reference occupational sector for the analysis as it is acknowledged that these shift workers may have achieved greater levels of health literacy and education compared with those working in other sectors. ${ }^{27}$ Independent variables significantly associated with the four outcomes in the univariable regression analyses were added to separate multivariable
Table 1 Demographic and health-related characteristics of shift workers $(n=1300)$

\begin{tabular}{|c|c|c|}
\hline Variables & $\mathbf{N}$ & $\%$ \\
\hline \multicolumn{3}{|l|}{ Country of residence } \\
\hline Ireland & 850 & 65.4 \\
\hline Northern Ireland & 450 & 34.6 \\
\hline \multicolumn{3}{|l|}{ Gender } \\
\hline Male & 672 & 51.7 \\
\hline Female & 628 & 48.3 \\
\hline \multicolumn{3}{|l|}{ Age category ${ }^{*}$} \\
\hline 18-34 years & 490 & 38.2 \\
\hline $35-54$ years & 606 & 47.2 \\
\hline $55-65$ years & 187 & 14.6 \\
\hline \multicolumn{3}{|l|}{ Marital status } \\
\hline Single never married & 528 & 40.6 \\
\hline Married and living with spouse & 637 & 49.0 \\
\hline Civil partnership & 27 & 2.1 \\
\hline Married and separated from spouse & 47 & 3.6 \\
\hline Divorced & 45 & 3.5 \\
\hline Widowed & 16 & 1.2 \\
\hline \multicolumn{3}{|l|}{ Socioeconomic status † } \\
\hline $\mathrm{ABC} 1$ & 599 & 48.2 \\
\hline C2DE & 644 & 51.8 \\
\hline \multicolumn{3}{|l|}{ Calculated BMı§ળ } \\
\hline Underweight & 30 & 2.7 \\
\hline Normal weight & 504 & 45.4 \\
\hline Overweight & 397 & 35.8 \\
\hline Obese & 179 & 16.1 \\
\hline
\end{tabular}

*Valid denominator $=1283$

†Based on the occupation of the head of household. ABC1 denotes upper middle class, middle class and lower middle class. C2DE denotes skilled working class, working class and nonworkers $^{15}$

$\ddagger$ Some participants declined to respond $(n=57)$

$\S$ Calculated based on self-reported height and weight and categorised according to the WHO BMI classification ${ }^{14}$

IValid denominator $=1110$

BMI, body mass index.

logistic regression models for the four outcomes. All independent variables were mutually adjusted for in the multivariable models for each of the four outcomes of interest. Significant results were determined by a value of $p<0.05$.

\section{RESULTS}

\section{Demographic characteristics}

Table 1 provides information on the shift workers' demographic characteristics. There was a similar proportion of men and women, and of those in both categories of SES. Middle-aged (35-54 years old) shift workers comprised the largest proportion of participants. 


\section{Shift work schedule and work environment characteristics}

Table 2 provides information on the characteristics of the shift workers' work schedule and work environment. The most common average shift length reported was 8-11 hours. In terms of the predominant pattern of shifts worked, those in the 'other' category and those working predominantly day shifts comprised the largest groups. Over half of participants had access to food preparation and storage facilities at work. Less than one-third had access to vending machines. Most participants reported receiving adequate work break times. The majority did not have access to leisure facilities at work.

\section{Dietary and physical activity characteristics}

Table 3 provides information on the shift workers' dietary behaviours and physical activity levels. Approximately $40 \%$ reported consuming five or more daily servings of fruits and vegetables, while $61 \%$ did not consume wholegrains on a daily basis. Over one-third consumed soft drinks at least once per week. Thirty-nine per cent adhered to national aerobic physical activity guidelines, while 59\% were engaged in minimal physical effort at work and approximately one-fifth reported mostly sedentary occupational behaviour.

\section{Multivariable regression analysis}

The univariable regression analyses which informed the multivariable regression models are available as (onlineonly) online supplementary tables $2-5$. Tables 4 and 5 combined present the four multivariable regression models with all independent variables listed.

\section{Fruit and vegetable intake}

Male shift workers (relative to women) and those in the lower C2DE social class (relative to those in the upper ABC1 class) were $45 \%(\mathrm{p}<0.001, \mathrm{OR}=0.55,95 \%$ CI 0.40 to $0.74)$ and $25 \%(\mathrm{p}=0.046, \mathrm{OR}=0.75,95 \%$ CI 0.57 to 0.99$)$ less likely to consume five or more daily portions of fruits and vegetables, respectively.

\section{Wholegrain intake}

Those exposed to shift work for 8 years or more (compared with those exposed for less) were $38 \%$ more likely ( $\mathrm{p}=0.02, \mathrm{OR}=1.38,95 \% \mathrm{CI} 1.05$ to 1.82 ) to consume wholegrains at least daily, while compared with those working mostly day shifts, participants working predominantly nights, rotating or other shift patterns were each over a third less likely to do so $(\mathrm{p}=0.011, \mathrm{OR}=0.61$, $95 \%$ CI 0.41 to $0.89, \mathrm{p}=0.026, \mathrm{OR}=0.65,95 \%$ CI 0.45 to 0.95 and $\mathrm{p}=0.002$, $\mathrm{OR}=0.65,95 \%$ CI 0.50 to 0.86 , respectively). Retail shift workers were $35 \%$ less likely $(\mathrm{p}=0.022$, $\mathrm{OR}=0.65,95 \% \mathrm{CI} 0.44$ to 0.94 ) to consume wholegrains on a daily basis compared with those working in health and social work services.

\section{Soft drinks intake}

Middle-aged shift workers (35-54years old) were half as likely $(\mathrm{p}<0.001, \mathrm{OR}=0.50,95 \% \mathrm{CI} 0.34$ to 0.73$)$ to consume soft drinks at least weekly relative to the
Table 2 Shift schedule and work environment characteristics of shift workers $(n=1300)$

\begin{tabular}{|c|c|c|}
\hline Variables & $\mathbf{N}$ & $\%$ \\
\hline \multicolumn{3}{|l|}{ Occupational sector } \\
\hline Accommodation and food services & 218 & 16.8 \\
\hline Health and social work & 355 & 27.3 \\
\hline Retail & 229 & 17.6 \\
\hline Manufacturing & 110 & 8.5 \\
\hline Other ${ }^{\star}$ & 388 & 29.8 \\
\hline \multicolumn{3}{|l|}{ Pattern of SW } \\
\hline Predominantly days & 460 & 35.4 \\
\hline Predominantly nights & 164 & 12.6 \\
\hline Predominantly rotating & 168 & 12.9 \\
\hline Other & 508 & 39.1 \\
\hline \multicolumn{3}{|l|}{ Duration of exposure to SW } \\
\hline$<8$ years & 622 & 47.8 \\
\hline$\geq 8$ years & 678 & 52.2 \\
\hline \multicolumn{3}{|l|}{ Average length of shift } \\
\hline$<8$ hours & 379 & 29.2 \\
\hline $8-11$ hours & 622 & 47.8 \\
\hline$\geq 12$ hours & 299 & 23.0 \\
\hline \multicolumn{3}{|l|}{$\begin{array}{l}\text { Availability and use of food preparation } \\
\text { facilities }\end{array}$} \\
\hline Yes & 685 & 52.7 \\
\hline No & 327 & 25.2 \\
\hline Not available & 288 & 22.1 \\
\hline \multicolumn{3}{|l|}{$\begin{array}{l}\text { Availability and use of food storage } \\
\text { facilities }\end{array}$} \\
\hline Yes & 784 & 60.3 \\
\hline No & 267 & 20.5 \\
\hline Not available & 249 & 19.2 \\
\hline \multicolumn{3}{|l|}{$\begin{array}{l}\text { Availability and use of vending } \\
\text { machines }\end{array}$} \\
\hline Yes & 355 & 27.3 \\
\hline No & 408 & 31.4 \\
\hline Not available & 537 & 41.3 \\
\hline \multicolumn{3}{|l|}{ Receiving adequate break times $\dagger$} \\
\hline Agree & 776 & 69.7 \\
\hline Disagree & 337 & 30.3 \\
\hline
\end{tabular}

Satisfied with healthy meal/snack

availability

\begin{tabular}{lrc} 
Agree & 551 & 59.3 \\
Disagree & 378 & 40.7 \\
Availability of leisure facilities & & \\
Yes & 142 & 10.9 \\
No & 1158 & 89.1 \\
\hline
\end{tabular}

*Denotes those employed in sectors of transport/communications, agriculture/animals, construction, call centre/telesales, computerrelated activity, distribution and logistics and finance/banking/ insurance

†Valid denominator $=1113$

$\ddagger$ Valid denominator $=929$

SW, shift work. 
Table 3 Dietary behaviours and physical activity levels of shift workers $(n=1300)$

\begin{tabular}{|c|c|c|}
\hline Variables & $\mathbf{N}$ & $\%$ \\
\hline \multicolumn{3}{|c|}{ Fruit and vegetable consumption* } \\
\hline$\geq 5$ servings/day & 522 & 40.2 \\
\hline$<5$ servings/day & 778 & 59.8 \\
\hline \multicolumn{3}{|l|}{ Wholegrain consumption* } \\
\hline$\geq 1$ serving per day & 512 & 39.4 \\
\hline$<1$ serving per day $†$ & 788 & 60.6 \\
\hline \multicolumn{3}{|l|}{ Soft drink consumption* } \\
\hline$\geq 1$ serving per week & 487 & 37.5 \\
\hline$<1$ serving per week $\neq$ & 813 & 62.5 \\
\hline \multicolumn{3}{|l|}{ Type of occupational PA } \\
\hline Mostly sitting & 262 & 20.2 \\
\hline Minimal physical effort & 762 & 58.6 \\
\hline Moderate physical effort & 212 & 16.3 \\
\hline Vigorous physical effort & 64 & 4.9 \\
\hline \multicolumn{3}{|c|}{ Time spent in MVPA per week§ી } \\
\hline$\geq 150 \mathrm{~min}$ & 509 & 39.2 \\
\hline$<150 \min$ & 789 & 60.8 \\
\hline
\end{tabular}

*Denotes frequency of consumption according to the Food Safety Authority of Ireland dietary guidelines ${ }^{16}$

†Denotes consumption multiple times per week, less than weekly or not at all

$\ddagger$ Denotes consumption less than weekly or not at all

$\S B a s e d$ on national and international physical activity guidelines $^{25} 26$

TValid denominator $=1298$

MVPA, moderate-vigorous physical activity; PA, physical activity.

youngest participants (18-34years old), while the oldest age group of shift workers were $67 \%$ less likely to consume soft drinks at least weekly relative to the youngest group $(\mathrm{p}<0.001, \mathrm{OR}=0.33,95 \% \mathrm{CI} 0.18$ to 0.59$)$. When compared with those working in health and social work, manufacturing employees were just over twice as likely $(\mathrm{p}=0.019$, $\mathrm{OR}=2.03,95 \%$ CI 1.12 to 3.68) to consume soft drinks at least once per week. Shift workers with access to vending machines at work (compared with those without) were $64 \%(\mathrm{p}=0.003, \mathrm{OR}=1.64,95 \% \mathrm{CI} 1.18$ to 2.27$)$ more likely to consume soft drinks at least once per week.

\section{Physical activity}

Middle-aged shift workers were $35 \%(\mathrm{p}=0.012, \mathrm{OR}=0.65$, $95 \%$ CI 0.46 to 0.91 ) less likely to adhere to national physical activity guidelines relative to the youngest participants, while those who did not receive adequate break times at work (relative to those who did) were $31 \%$ ( $\mathrm{p}=0.026, \mathrm{OR}=0.69,95 \%$ CI 0.49 to 0.96$)$ less likely to do so.

\section{DISCUSSION}

This study identified factors pertaining to the individual, shift work exposure and the workplace environment that were independently associated with adherence among a large cohort of shift workers employed on the island of Ireland to selected indicators of population dietary and physical activity guidelines. Overall, adherence among participants to these guidelines was suboptimal-less than half were adherent to each of the indicators of interest. With respect to dietary intake, this supports previous studies which have demonstrated lower intakes of fruits, vegetables and dietary fibre ${ }^{22-24}$ among shift workers compared with day workers, as well as lower than recommended intakes of carbohydrates. ${ }^{28}$ Consistent observations of higher intakes of soft drinks, and of poorer dietary quality and quantity, have also been reported among shift workers compared with non-shift workers. ${ }^{10}$ In contrast, previous research has yielded conflicting results regarding the leisure physical activity of shift workers, ${ }^{5}$ making comparison with our findings challenging. The low level of occupational activity, however, among participants is consistent with some previous data ${ }^{29}$ although others have reported greater levels of the same compared with day workers. ${ }^{30}$ Such differences may be explained by variable methodological approaches to measuring physical activity levels across these studies-nonetheless, there are significant risks to physical and mental health associated with physical inactivity and sedentary lifestyles. ${ }^{31}$

We found that men and those of lower SES were significantly less likely to consume the recommended daily servings of fruits and vegetables. Social class and gender differences in intake of these foods have been described previously in the general Irish adult population ${ }^{19}{ }^{32}-$ however, to the authors' knowledge, this is the first time this finding has been confirmed specifically in a range of shift workers. One study conducted on airline shift workers found lower fruit and vegetable intake among men without in-flight work compared with day and in-flight workers. ${ }^{23}$

Differences in dietary quality according to age among shift workers have been reported previously. ${ }^{33}$ Age category also emerged as a significant factor in our analysis. Younger shift workers, compared with those who were middle-aged and older, were more likely to consume soft drinks at least weekly. In the general Irish population, young adults aged 15-34 years have been shown to have the highest intakes of sugar-sweetened beverages, many of which are soft drinks. ${ }^{19}$ In contrast, middle-aged shift workers, compared with the youngest group, were less likely to adhere to aerobic physical activity guidelines. Declining levels of awareness of and adherence to these guidelines with age have been reported in the Irish adult population which may in part explain this finding. ${ }^{34}$

We examined several factors pertaining to shift work exposure-duration of exposure, occupational sector, average shift length, and predominant shift pattern. We found, relative to those working in health and social work, retail sector shift workers were less likely to consume wholegrain foods daily, while manufacturing workers were more likely to consume soft drinks at least weeklythe latter supports prior research demonstrating greater 


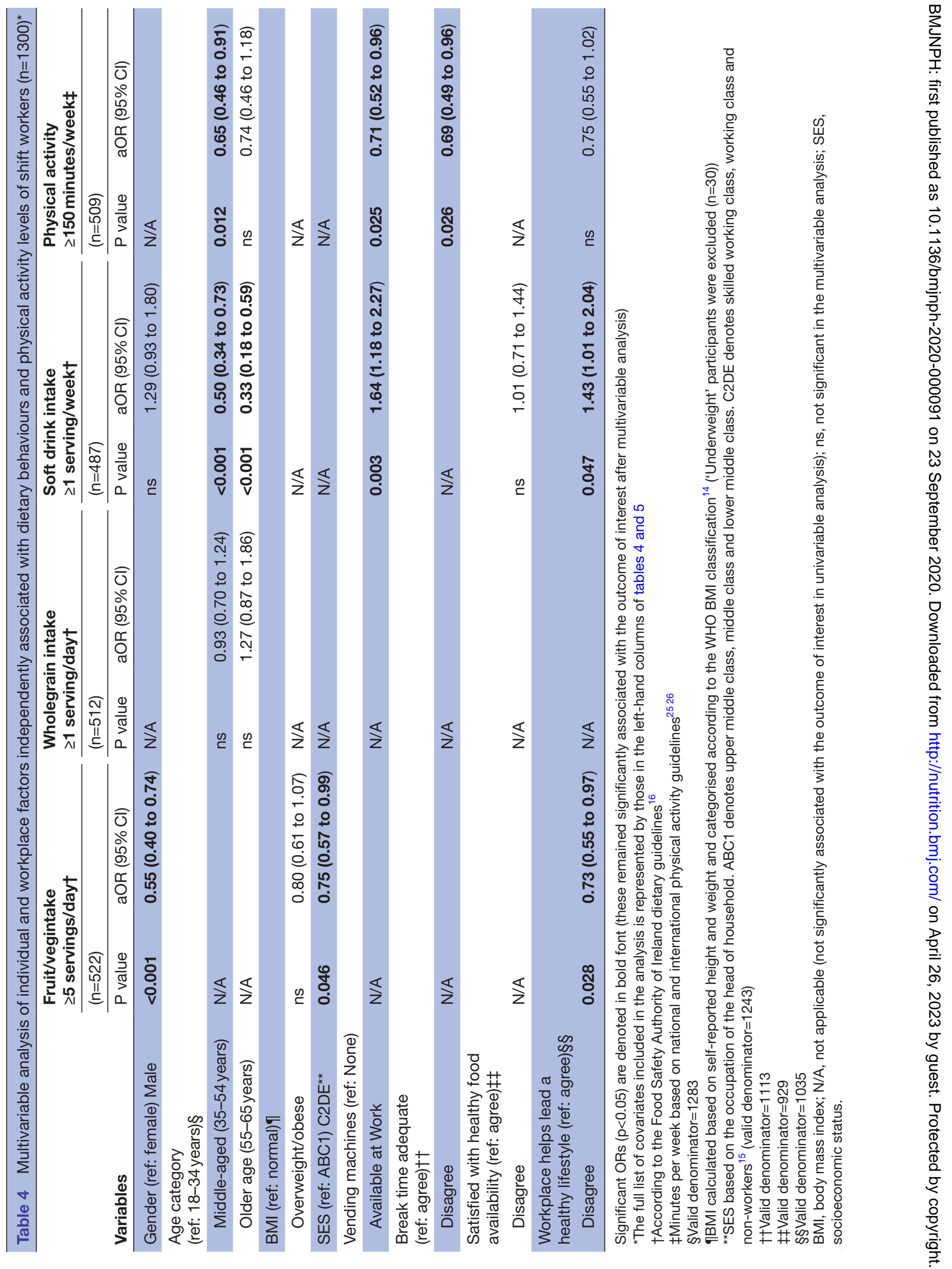




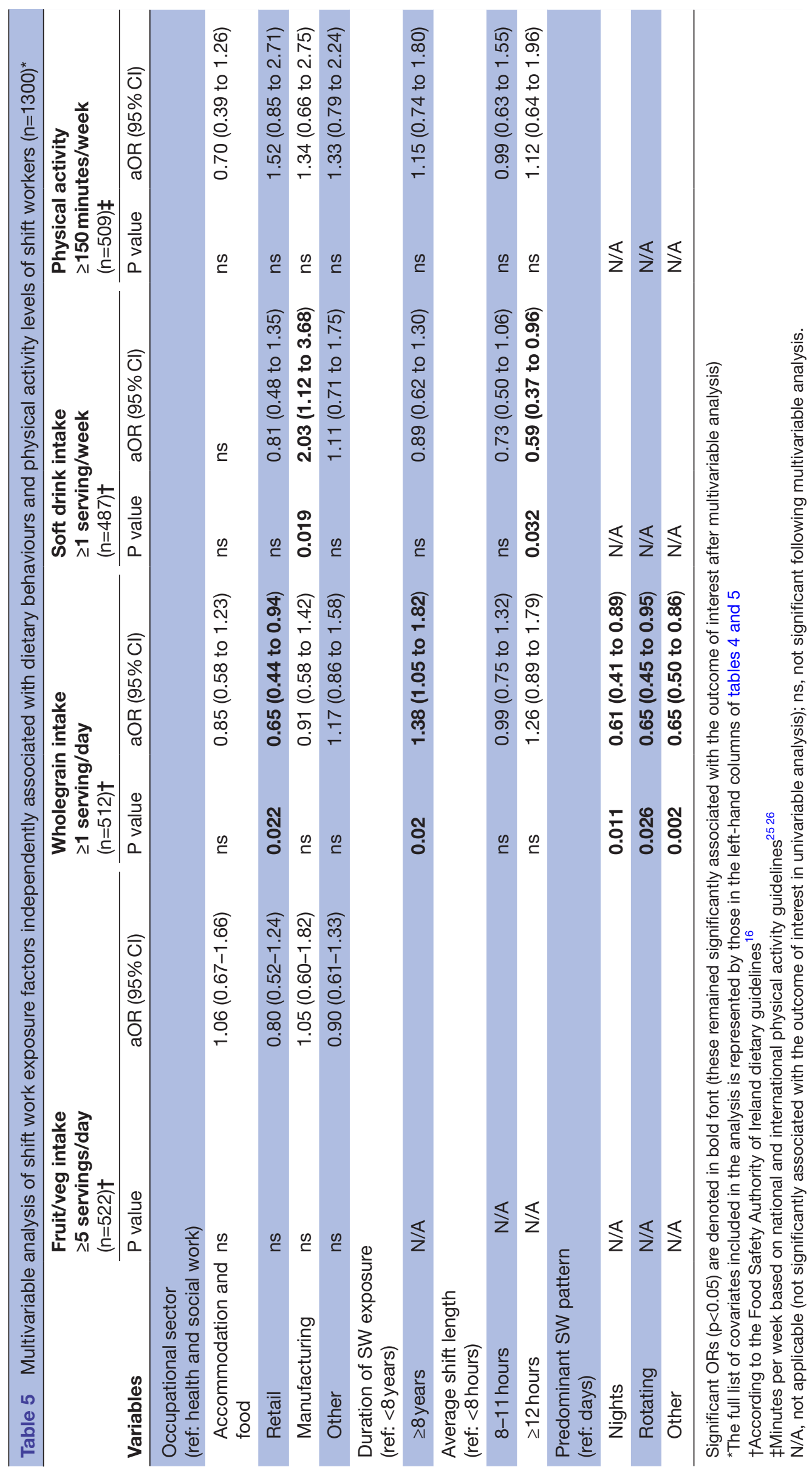


energy intake and poorer dietary quality in the manufacturing occupational subgroup. ${ }^{22}$ Participants working predominantly non-day shifts were less likely to consume wholegrain foods daily, which is somewhat consistent with previous findings of poorer dietary quality among night and rotating shift workers compared with day workers. ${ }^{335}$ However, we did not observe any significant differences in consumption of fruits and vegetables or soft drinks across shift pattern. Cumulative years employed in shift work also emerged as a significant factor in relation to daily wholegrain intake even when adjusted for age category, which may suggest improvements in health and nutritional knowledge among those with greater experience working in shift systems.

With regard to the work environment of participants, we observed two main findings. Those with access to vending machines at work, compared with those without, were more likely to consume soft drinks at least weeklyan important finding given improvements in availability (and price) of healthier choices in vending machines have been shown to improve sales of healthier products. ${ }^{36}{ }^{37}$ In addition, those who reported that they did not receive adequate break times at work were less likely to be sufficiently active compared with those who did, supporting previous Irish research which identified a perceived lack of time to be a barrier to physical activity among shift workers. ${ }^{38}$

\section{Implications of findings}

The gender, age and social class differences we observed across specific dietary behaviours highlight that nutritional aspects of health education and interventions for shift workers which seek to improve their adherence to population dietary guidelines should be developed with these characteristics in mind. Our findings also highlight the need to target middle-aged shift workers with workplace interventions which aim to improve their adherence to population physical activity guidelines.

Our findings regarding the shift work schedule and occupation of participants in relation to their adherence to selected indicators of dietary and physical activity guidelines may help employers to devise and adapt workplace policy and interventions which aim to improve adherence among employees to such guidelines. The workplace is a social context within which shift workers may spend a large amount of time and should support health-promoting lifestyle behaviours. ${ }^{39}$ This study has highlighted that provision for shift workers of healthy vending machines, food preparation and storage facilities, and adequate break times should be a priority for employers.

\section{Strengths and limitations}

The study population was large in size, and was demographically, geographically and occupationally representative of the Irish shift work population, about whom little is known from a research perspective to date. Factors independently associated with adherence among participants to selected indicators of dietary and physical activity guidelines were identified, the optimisation of which is of importance from a public and occupational health perspective. Although a non-shift worker control group was not available to us against which the adherence of participants could be compared, nationally representative data for the general adult populations of RoI and NI were included, where appropriate, for comparison and context.

The cross-sectional design of this study precludes the potential to draw causal inferences from findings. Data were collected using a questionnaire, raising the possibility of recall and self-report bias pertaining to potential misreporting of weight, height, dietary behaviours and physical activity. Minor differences between the dietary and physical activity guidelines used and the corresponding questions in the questionnaire may have led to a slight underestimation or overestimation of adherence to the selected indicators of the guidelines among participants. The study questionnaire did not capture all domains of shift work-further research is needed to examine dietary and physical activity behaviours across different shift schedules and systems. Occupational physical activity, although not examined as an outcome in our study, remains an important consideration in relation to the health of shift workers. The possibility of residual confounding due to factors not included or measured in our analysis cannot be excluded. Finally, multicollinearity was not examined-as such the possibility of correlation between independent variables remains, which may have affected the validity of our findings.

\section{CONCLUSIONS}

Individual, work schedule and workplace environmentrelated factors were independently associated with selected indicators of adherence to dietary and physical activity guidelines in this cohort of shift workers. Shift workers face unique challenges to their health at the biological, psychological and social level. Tailored occupational health measures are required which address these challenges and provide solutions for them. This study has provided insights which may contribute to the development of such measures, targeting individual and organisational factors to protect the health of this vulnerable subpopulation of the global workforce.

\section{Author affiliations}

${ }^{1}$ Department of Public Health, Merlin Park Regional Hospital, Galway, Ireland ${ }^{2}$ School of Public Health, Physiotherapy and Sports Science, University College Dublin, Dublin, Ireland

${ }^{3}$ School of Biological Sciences, Technological University of Dublin, Dublin, Ireland

${ }^{4}$ Nutrition Innovation Centre for Food and Health (NICHE), Centre for Molecular Biosciences, Ulster University, Coleraine, UK

${ }^{5}$ Institute of Food and Health, University College Dublin, Dublin, Ireland

${ }^{6}$ School of Agriculture and Food Science, University College Dublin, Dublin, Ireland

Twitter Ciara Kelly @theirishbalance and L Kirsty Pourshahidi @DrKirstyP

Acknowledgements The authors thank the shift workers who participated in this study. 
Contributors This study was a secondary analysis of data collected for a previous larger study commissioned by safefood entitled 'Managing Food on Shift Work'. CC was the project lead for the original safefood study, in collaboration with JK and MBL. FN and KP contributed to data collection, analysis and interpretation for the original safefood study. CK and CC conceptualised the present study and its methodology. CK led the statistical analysis and data interpretation, and wrote the manuscript. CC supervised the present study and contributed to data analysis and interpretation, and the writing and critical review of the manuscript. VOB and MBL contributed to data interpretation and the critical review of the manuscript. FN, KP and JK contributed to the critical review of the manuscript. All authors read the manuscript, contributed comments to its revision, and have approved and agreed to the final version. CK submitted the manuscript and is responsible for the overall content as guarantor.

Funding The original study was supported by safefood, the Food Safety Promotion Board, under Grant No. (10-2013).

Competing interests None declared.

Patient consent for publication Not required.

Ethics approval An ethics exemption application was approved by the Taught Masters Research Ethics Committee (TM-REC) of the University College Dublin (UCD) School of Public Health, Physiotherapy and Sports Science on the basis of previously granted ethical approval for the original safefood study by the Dublin Institute of Technology (DIT) Research Ethics Committee in 2014 (Ethical Clearance Reference 14-09) - this application and approval from DIT were also reviewed and agreed by the Biomedical Sciences Ethics Committee of the University of Ulster (UU), Coleraine, Northern Ireland at the time. No new data were collected for this study.

Provenance and peer review Not commissioned; externally peer reviewed.

Data availability statement All data relevant to the study are included in the article or uploaded as supplementary information.

Open access This is an open access article distributed in accordance with the Creative Commons Attribution Non Commercial (CC BY-NC 4.0) license, which permits others to distribute, remix, adapt, build upon this work non-commercially, and license their derivative works on different terms, provided the original work is properly cited, appropriate credit is given, any changes made indicated, and the use is non-commercial. See: http://creativecommons.org/licenses/by-nc/4.0/.

\section{ORCID iD}

Ciara Kelly http://orcid.org/0000-0001-5697-9957

\section{REFERENCES}

1 The Council of the European Union. Directive 2000/34/EC of the European Parliament and of the Council of 22 June 2000 amending Council Directive 93/104/EC 'concerning certain aspects of the organisation of working time to cover sectors and activities excluded from that Directive.'. Official Journal 1993;|195:41-5.

2 Health and Safety Authority. 'Guidance for Employers and Employees on Night and Shift Work.'. Dublin: Health and Safety Authority, 2012. https://www.hsa.ie/eng/Publications_and_Forms/Publications/ Healthcare_Sector/Night_and_Shift_Work_2012.pdf

3 Eurofound. 'Changes over time - First findings from the fifth European Working Conditions Survey.'. Luxembourg: Publications Office of the European Union, 2010. https://www.eurofound.europa. eu/sites/default/files/ef_publication/field_ef_document/ef1182en.pdf

4 Eurofound. 'First findings: Sixth European Working Conditions Survey'. Luxembourg: Publications Office of the European Union, 2015. https://www.eurofound.europa.eu/sites/default/files/ef_ publication/field_ef_document/ef1634en.pdf

5 Nea FM, Kearney J, Livingstone MBE, et al. Dietary and lifestyle habits and the associated health risks in shift workers. Nutr Res Rev 2015;28:143-66.

6 Vogel M, Braungardt T, Meyer W, et al. The effects of shift work on physical and mental health. J Neural Transm 2012;119:1121-32.

7 IARC Monographs Vol 124 group. Carcinogenicity of night shift work. Lancet Oncol 2019;20:1058-9.

8 Lowden A, Moreno C, Holmbäck U, et al. Eating and shift work - effects on habits, metabolism and performance. Scand J Work Environ Health 2010;36:150-62.

9 Zhao I, Turner C. The impact of shift work on people's daily health habits and adverse health outcomes. Australian $J$ of Adv Nursing 2008;25:8-22.
10 Souza RV, Sarmento RA, de Almeida JC, et al. The effect of shift work on eating habits: a systematic review. Scand $J$ Work Environ Health 2019;45:7-21.

11 Atkinson G, Fullick S, Grindey C, et al. Exercise, energy balance and the shift worker. Sports Med 2008;38:671-85.

12 Nea FM, Pourshahidi LK, Kearney JM, et al. A qualitative exploration of the shift work experience: the perceived effect on eating habits, lifestyle behaviours and psychosocial wellbeing. $J$ Public Health 2018;40:e482-92.

13 Safefood. Managing food on shift work: an exploration of the eating patterns, related lifestyle behaviours and experiences of shift workers on the island of Ireland. Co. Cork, Ireland: Safefood, 2016. http:// www.safefood.eu/SafeFood/media/SafeFoodLibrary/Documents/ Publications/Research\%20Reports/Managing-food-on-shift-work Island-of-Ireland-October-2016.pdf

14 World Health Organisation. Body mass index: BMI [World Health Organisation website], 2019. Available: http://www.euro.who.int/en/ health-topics/disease-prevention/nutrition/a-healthy-lifestyle/bodymass-index-bmi [Accessed 14 Feb 2020].

15 National Readership Survey. Social grade [National Readership Survey website], 2015. Available: http://www.nrs.co.uk/nrs-print/ lifestyle-and-classification-data/social-grade/ [Accessed 14 Feb 2020]

16 Food Safety Authority of Ireland. Healthy eating, food safety and food legislation: a guide supporting the healthy Ireland food pyramid. Dublin, Ireland: FSAI, 2016.

17 Wang X, Ouyang Y, Liu J, et al. Fruit and vegetable consumption and mortality from all causes, cardiovascular disease, and cancer: systematic review and dose-response meta-analysis of prospective cohort studies. BMJ 2014;349:g4490.

18 Reynolds A, Mann J, Cummings J, et al. Carbohydrate quality and human health: a series of systematic reviews and meta-analyses. Lancet 2019;393:434-45.

19 Department of Health. Healthy Ireland 2018: a summary of findings. Dublin, Ireland: Government Publications, 2018. https://www.hse.ie/ eng/about/who/healthwellbeing/healthy-ireland/publications/healthyireland-survey-2018.pdf

20 Corrigan D, Scarlett M. Health survey (NI): first results 2017/18. Belfast, Northern Ireland: Department of Health, 2018. https://www. health-ni.gov.uk/sites/default/files/publications/health/hsni-firstresults-17-18.pdf

21 Irish Universities Nutrition Alliance. National adult nutrition survey: summary report. Cork, Ireland: Irish Universities Nutrition Alliance, 2011. https://irp-cdn.multiscreensite.com/46a7ad27/files/uploaded/ The\%20National\%20Adult\%20Nutrition\%20Survey\%20Summary\% 20Report\%20March\%202011.pdf

22 Nakamura M, Miura A, Nagahata T, et al. Dietary intake and dinner timing among shift workers in Japan. J Occup Health 2018:60:467-74.

23 Hemiö K, Puttonen S, Viitasalo K, et al. Food and nutrient intake among workers with different shift systems. Occup Environ Med 2015;72:513-20.

24 Balieiro LCT, Rossato LT, Waterhouse J, et al. Nutritional status and eating habits of bus drivers during the day and night. Chronobiol Int 2014;31:1123-9.

25 Department of Health. Get Ireland active: national physical activity action plan for Ireland. Ireland: Department of Health, 2016. https:// www.getirelandactive.ie/Professionals/National-PA-Plan.pdf

26 World Health Organisation. Global recommendations on physical activity for health. Geneva, Switzerland: WHO, 2010. https://apps. who.int/iris/bitstream/handle/10665/44399/9789241599979_eng.pdf; jsessionid $=283$ A70241353F8D9193F6FA2EA6B8B53? sequence $=1$

27 Profis M, Simon-Tuval T. The influence of healthcare workers' occupation on health promoting lifestyle profile. Ind Health 2016;54:439-47.

28 Heath G, Coates A, Sargent C, et al. Sleep duration and chronic fatigue are differently associated with the dietary profile of shift workers. Nutrients 2016;8:E771.

29 Hulsegge G, Gupta N, Holtermann A, et al. Shift workers have similar leisure-time physical activity levels as day workers but are more sedentary at work. Scand J Work Environ Health 2017;43:127-35.

30 Loef B, van der Beek AJ, Holtermann A, et al. Objectively measured physical activity of hospital shift workers. Scand J Work Environ Health 2018;44:265-73.

31 Guthold R, Stevens GA, Riley LM, et al. Worldwide trends in insufficient physical activity from 2001 to 2016: a pooled analysis of 358 population-based surveys with 1.9 million participants. Lancet Glob Health 2018;6:e1077-86.

32 National Nutrition Surveillance Centre. Dietary habits of the Irish population: results from SLÁN. Dublin: University College Dublin, 2003. http://www.ucd.ie/issda/static/documentation/slan/diethab.pdf 
33 Morikawa Y, Miura K, Sasaki S, et al. Evaluation of the effects of shift work on nutrient intake: a cross-sectional study. J Occup Health 2008;50:270-8

34 Department of Health. Healthy ireland: survey report 2019. Dublin: Government Publications, 2019. https://assets.gov.ie/41141/e5d6 fea3a59a4720b081893e11fe299e.pdf

35 Bonnell EK, Huggins CE, Huggins CT, et al. Influences on dietary choices during day versus night shift in shift workers: a mixed methods study. Nutrients 2017;9:E193.

36 Gupta CC, Coates AM, Dorrian J, et al. The factors influencing the eating behaviour of shiftworkers: what, when, where and why. Ind Health 2019;57:419-53.
37 Grech A, Allman-Farinelli M. A systematic literature review of nutrition interventions in vending machines that encourage consumers to make healthier choices. Obes Rev 2015;16:1030-41.

38 Nea FM, Pourshahidi LK, Kearney J, et al. A qualitative exploration of the shift work experience: the perceived barriers and facilitators to a healthier lifestyle and the role of the workplace environment. J Occup Environ Med 2017;59:1153-60.

39 Lassen AD, Fagt S, Lennernäs $M$, et al. The impact of worksite interventions promoting healthier food and/or physical activity habits among employees working 'around the clock' hours: a systematic review. Food Nutr Res 2018:62:1115. 